\title{
Two-Photon Photoexcited Photodynamic Therapy with Water-Soluble Fullerenol Serving as the Highly Effective Two-Photon Photosensitizer Against Multidrug-Resistant Bacteria
}

This article was published in the following Dove Press journal:

International Journal of Nanomedicine

\begin{abstract}
Wen-Shuo Kuo ${ }^{1,2}$
Chia-Yuan Chang ${ }^{3}$

Jui-Chang Liu $^{4}$

Jian-Hua Chen ${ }^{5,6, *}$

Edmund Cheung So (D) $^{5-7, *}$

Ping-Ching $\mathrm{Wu}^{8, *}$

'School of Chemistry and Materials Science, Nanjing University of Information Science and Technology, Nanjing, Jiangsu 210044, People's Republic of China; ${ }^{2}$ Allergy \& Clinical Immunology Research Center, National Cheng Kung University Hospital, College of Medicine, National Cheng Kung University, Tainan 70I, Taiwan Republic of China; ${ }^{3}$ Department of Mechanical Engineering, National Cheng Kung University, Tainan 70I, Taiwan Republic of China; ${ }^{4}$ Department of Biochemistry and Molecular Biology, National Cheng Kung University, Tainan 70I, Taiwan Republic of China; ${ }^{5}$ Department of Anesthesia \& Medicine Research, An Nan Hospital, China Medical University, Tainan 709, Taiwan Republic of China; ' Department of Anesthesia, China Medical University, Taichung 404, Taiwan Republic of China; ${ }^{7}$ Graduate Institute of Medical Sciences, Chang Jung Christian University, Tainan 7II, Taiwan Republic of China; ${ }^{8}$ Department of Biomedical Engineering, National Cheng Kung University, Tainan 70I, Taiwan Republic of China
\end{abstract}

*These authors contributed equally to this work

Correspondence: Jian-Hua Chen; Ping-Ching Wu

Email aptx4869jfk@gmail.com;

wbcxyz@bme.ncku.edu.tw
Background: Multidrug-resistant (MDR) bacterial strain is a serious medical problem. Methicillin-resistant Staphylococcus aureus (MRSA) is resistant to many antibiotics and is often associated with several diseases such as arthritis, osteomyelitis, and endocarditis. The development of an alternative treatment for eliminating MDR bacteria such as MRSA has attracted a considerable amount of research attention. Moreover, the development of a material for highly efficient generation of reactive oxygen species (ROS) involving twophoton photodynamic therapy (PDT) is currently desirable.

Materials and Methods: We present an example demonstrating that the use of watersoluble $\mathrm{C}_{60}(\mathrm{OH})_{30}$ fullerenol with a 0.89 singlet oxygen quantum yield serving as a photosensitizer in PDT has the superior ability in effectively generating ROS.

Results: It has ultra-low energy (228.80 $\mathrm{nJ}$ pixel $^{-1}$ ) and can perform 900 scans under twophoton excitation (TPE) in the near-infrared region $(760 \mathrm{~nm})$ to completely eliminate the MDR species. Furthermore, the favorable two-photon properties are absorption of approximately $760 \mathrm{~nm}$ in wavelength, absolute cross-section of approximately 1187.50 GöeppertMayer units, lifetime of $6.640 \mathrm{~ns}$, ratio of radiative to nonradiative decay rates of approximately 0.053 , and two-photon stability under TPE

Conclusion: This enabled water-soluble $\mathrm{C}_{60}(\mathrm{OH})_{30}$ fullerenol to act as a promising twophoton photosensitizer proceeding with PDT to easily eliminate MDR species.

Keywords: methicillin-resistant Staphylococcus aureus, two-photon photodynamic therapy, water-soluble fullerenol, two-photon excitation, near-infrared region

\section{Introduction}

PDT is based on the concept that photosensitizer (PS) molecules can be preferentially localized in areas of pathological changes during systemic administration. ${ }^{1}$ ROS, such as singlet oxygen $\left({ }^{1} \mathrm{O}_{2}\right)$, superoxide radical anion $\left(\mathrm{O}_{2}{ }^{-}\right)$, and other free radicals, are the main cytotoxic substances that can irreversibly damage treated analytes. ${ }^{2}$ However, combining nanomaterials with ROS in PDT has emerged as a new field of interdisciplinary research. Over the past decade, nanoparticulate agents have been applied in both pharmaceutical research and clinical settings. ${ }^{3}$ The constantly increasing interest in novel nanotechnology platforms for biomedical applications has stimulated the investigation of carbon nanomaterials, including fullerenes and their most prominent representative $-\mathrm{C}_{60}$ fullerene. ${ }^{4}$ Pristine unmodified $\mathrm{C}_{60}$ fullerene is a lipophilic, 
spheroidal, and symmetrical molecule with a diameter of $0.72 \mathrm{~nm} .{ }^{5}$ Because of the specific packing of atoms in pentagonal and hexagonal units, the surface of $\mathrm{C}_{60}$ is three times smaller than that expected for biological molecules with the same molecular weight of $720 \mathrm{Da}^{6}$ The unusual structure of $\mathrm{C}_{60}$ fullerene determines its unique physicochemical properties and biological activities. ${ }^{3,6,7} \mathrm{C}_{60}$ fullerene is a potential regulator of oxidative balance in biological systems. Because a $\mathrm{C}_{60}$ molecule consists entirely of $\mathrm{sp}^{2}$-hybridized carbon atoms, it can generate ROS after light irradiation. $\mathrm{C}_{60}$ fullerene exhibits greater photostability and less photobleaching than conventional photosensitizing molecules. ${ }^{8}$

Materials exhibiting two-photon properties have attracted considerable attention because of their promising applications not only in the growing field of biomedical imaging but also in PDT. ${ }^{9-13}$ Carbon-based materials, ${ }^{14}$ and $\mathrm{C}_{60}$ fullerene, in particular, have been recently discovered to exhibit two-photon properties. In this study, synthesized water-soluble $\mathrm{C}_{60}(\mathrm{OH})_{30}$ fullerenols were used to design a two-photon PS coupled with TPE (228.80 nJ pixel $\left.{ }^{-1}\right)$. For the calculation of power after the objective of the sample, please refer to the Materials and Methods section. As depicted in Figure 1A, the $x-y$ focal point and the $z$-axis resolution of the laser system were approximately 0.3566 and $0.9168 \mu \mathrm{m}$, respectively. This achieved high efficacy with ultra-low energy (228.80 nJ pixel $^{-1}$, with 900 scans, approximately 3.6698 s of total effective exposure time; $4.0776 \mathrm{~ms} \mathrm{scan}^{-1}$, scan area 200 $\mu \mathrm{m} \times 200 \mu \mathrm{m}$. Please refer to the Materials and Methods for calculation) irradiation using a femtosecond laser with approximately $3.6698 \mathrm{~s}$ of photoexcitation. This irradiation resulted in nearly $100 \%$ elimination of a MDR strain of gram-positive MRSA. Thus, water-soluble $\mathrm{C}_{60}(\mathrm{OH})_{30}$ can serve as a promising agent to efficiently eliminate bacteria using TPE.

\section{Materials and Methods}

\section{Preparation and Characterization of Water-Soluble Fullerenol, $\mathrm{C}_{60}(\mathrm{OH})_{30}{ }^{15}$}

Raw fullerene was obtained commercially (Sigma-Aldrich, St. Louis, MO, USA), and the $\mathrm{C}_{60}(\mathrm{OH})_{12}$ precursor was produced, as previously described. First, 30\% hydrogen peroxide solution was added to the starting material, and the mixture was vigorously stirred at $60{ }^{\circ} \mathrm{C}$ under air. After cooling, a mixture of solvents comprising 2-propanol, diethyl ether, and hexane was added into the solution, which was subsequently centrifuged and decanted. The remaining solid was washed twice with diethyl ether through the general ultrasonic centrifugation and decantation procedures. Finally, the end product of water-soluble $\mathrm{C}_{60}(\mathrm{OH})_{30}$ was obtained by drying the residue under vacuum at room temperature. The weight of the end product was calibrated through thermal gravimetric analysis. The morphology of the end product was observed using a high-resolution transmission electron microscopy (HRTEM, JEOL 3010, Akishima, Tokyo, Japan) at a resolution
A

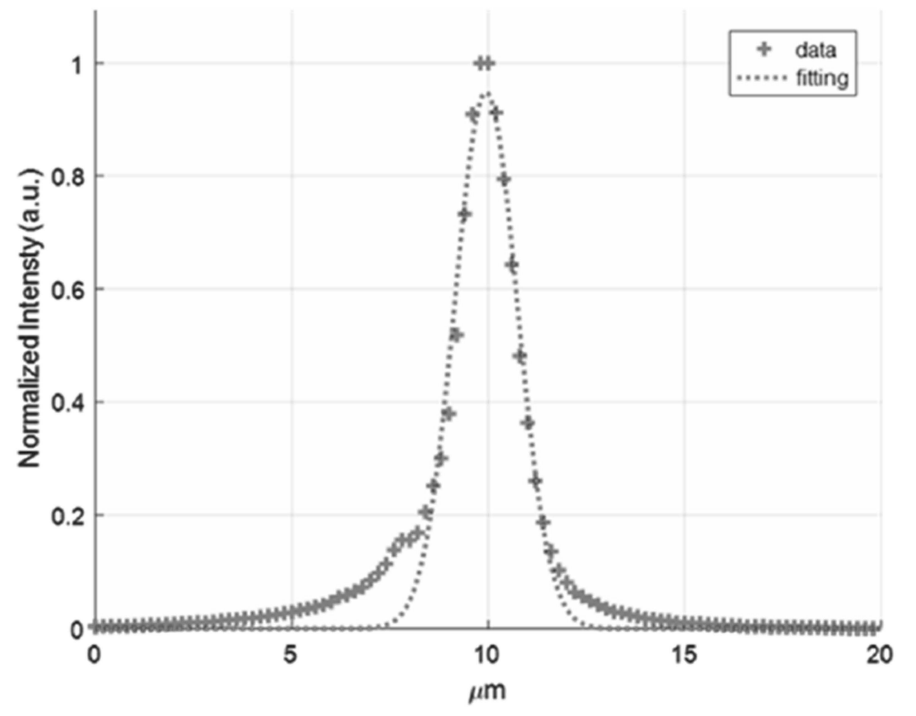

B

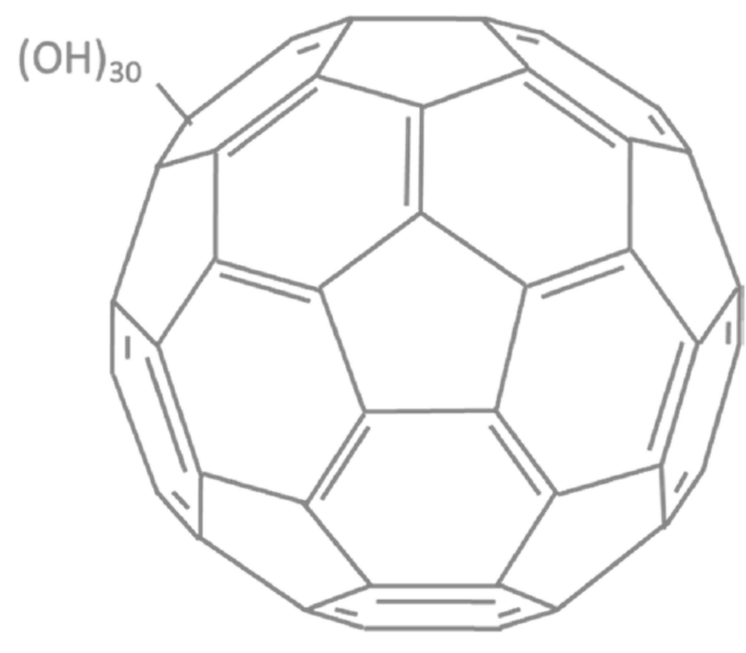

Figure I (A) According to the z-axis scan of a gold thin film used to measure the signal of second harmonic generation at different positions, the $z$-axis resolution of the laser system (full width at half maximum) is approximately $0.9168 \mu \mathrm{m}$ (fitting using Gaussian function). (B) Illustrative graph of synthesized water-soluble fullerenol. 
of approximately $1.05 \pm 0.02 \mathrm{~nm}$. The dynamic light scattering (DLS, Malvern Nano-ZS90, Worcestershire, West Midlands, UK) was also used to determine the size of nanomaterials. The exposed functional groups of the asprepared nanomaterials were first examined through Fourier-transform infrared spectroscopy (FTIR) spectroscopy (RX1, PerkinElmer, Waltham, MA, USA). Ultraviolet-visible (UV-vis) spectroscopy of the nanomaterials was conducted using a spectrometer (U-4100, Hitachi, Chiyoda-ku, Tokyo, Japan). The surface chemistry of the fullerenol was examined through X-ray photoelectron spectroscopy (XPS, PHI 5000 spectrometer (VersaProbe, Chanhassen, MN, USA). The molecular weight of fullerenol was determined using a field desorption (FD) mass spectrometer (AccuTOF, GCx-plus, JEOL, Akishima, Tokyo, Japan), and the number of hydroxyl groups was confirmed to be 30 based on the results (Supplementary Information, Figure S1).

\section{Bacterial Culture}

MRSA (ATCC 27659) was grown in $\mathrm{pH} 7.2$ of brain heart infusion (DIFCO 0418, BD, Franklin Lakes, NJ, USA) and incubated at $37^{\circ} \mathrm{C}$.

\section{Biocompatibility Assay with Colony Forming Unit (CFU) Counting Method}

MRSA $\left(\mathrm{OD}_{600} \sim 0.05\right)$ was added with material $(0-10 \mu \mathrm{g}$ $\mathrm{mL}^{-1}$ ) and incubated for $3 \mathrm{~h}$ at $37^{\circ} \mathrm{C}$. After incubation, the mixture was centrifuged and the pellets of bacteria were diluted $\left(\mathrm{OD}_{600} \sim 0.05\right)$. A dilution factor of $10^{-5}$ to $10^{-8}$ was then conducted in the incubated bacteria and plated on the agar plates. The plates remain in an incubator (at $37^{\circ} \mathrm{C}$ ) overnight. To prevent the possibility of confounding following ROS generation or PDT, the material was inadvertently exposed to white light, which could lead to the experiment being compromised. The relevant experiments were done in the dark in order to avoid ROS production when the material was exposed to the light and was used in all of the following photochemistry-related experiments. The number of surviving bacteria was determined and expressed as a percentage (\%) that corresponded to the unit of CFU $\mathrm{mL}^{-1}$ after incubation. Data are means $\pm \mathrm{SD}(\mathrm{n}=6)$.

\section{Singlet Oxygen Quantum Yield $\left(\psi_{\Delta}\right)$ Measurement ${ }^{16,17}$}

According to the previous study, $\psi_{\Delta}$ can be obtained. $\psi_{\Delta}$ measurements were carried out in $\mathrm{D}_{2} \mathrm{O}$ at $355 \mathrm{~nm}$, using meso-tetra(4-sulfonatophenyl)porphine dihydrochloride (TSPP, Sigma-Aldrich, St. Louis, MO, USA) as a reference $\left(\psi_{\Delta}=0.64\right)$.

\section{Fluorescence Quantum Yield (QY) Measurement $^{18-20}$}

The relative PL QY of contrast agent is usually the ratio of the emitted photons to the absorbed photons and is given as follows:

$$
\mathrm{QY}=\mathrm{QY} \text { ref }\left(\eta^{2} / \eta_{\text {ref }}^{2}\right)(I / A)\left(A_{\text {ref }} / I_{\text {ref }}\right)
$$

where $\mathrm{QY}_{\text {ref }}=0.28$ is the QY of Cy5.5 dissolved in dimethyl sulfoxide (DMSO, Sigma-Aldrich, St. Louis, $\mathrm{MO}, \mathrm{USA}$ ) as a reference, $\eta$ is the refractive index of $\mathrm{ddH}_{2} \mathrm{O}=1.33$ ( $\eta_{\text {ref }}$ of $\left.\mathrm{DMSO}=1.48\right), I$ is the integrated fluorescence intensity and $A$ is the absorbance at the excitation wavelength. One-photon excitation (OPE) or TPE yields the same QY.

\section{Femtosecond Laser Optical System for the Measurements of Two-Photon Absorption (TPA) and Two-Photon Luminescence (TPL) ${ }^{21-25}$}

The home-made femtosecond titanium-sapphire (ti-sa) laser optical system (a repetition rate of $80 \mathrm{MHz}$; Tsunami, Spectra-Physics, Santa Clara, CA, USA) was used according to the previous studies. TPA measurement. With $2 \mathrm{~m} \mathrm{~ms}^{-1}$ speed of the galvanometer scanner, the excitation spectrum was measured as 720-820 nm with an excitation power of 2.8 $\mathrm{mW}$ [this is the power before objective; the power after objective (or on sample) is $0.9856 \mathrm{~mW}$ or 98.56 nJoule $\operatorname{pixel}^{-1}\left(\mathrm{~nJ}\right.$ pixel $\left.\left.^{-1}\right)\right]$. Therefore, the relative TPA spectra as function of excitation wavelength for the water-soluble $\mathrm{C}_{60}$ $(\mathrm{OH})_{30}$ fullerenol was measured. Measurement of TPL spectra. The material was exposed to TPE from the femtosecond laser at an excitation wavelength of $760 \mathrm{~nm}$, a scanning area of $200 \mu \mathrm{m} \times 200 \mu \mathrm{m}$, a frequency of $10 \mathrm{kHz}$, an exposure time of $1.638 \mathrm{~s} /(\mathrm{scan}$, pixel $)=100 \mu \mathrm{s}, 128 \times 128$ pixels $\operatorname{scan}^{-1}$, and a pixel area of $1562.5 \mathrm{~nm} \times 1562.5 \mathrm{~nm}$. The focal spot area was calculated as $\pi d^{2} / 4$, where $d=0.61 \lambda$ / numerical aperture $(N A)$ is the full width at half maximum of the beam waist. For instance, at the $\mathrm{x}-\mathrm{y}$ axis focal spot with $760 \mathrm{~nm}$ excitation and a $40 \times$ oil-immersion objective with an $N A$ of $1.3, d=0.61 \times 800 \mathrm{~nm} / 1.3=375.38 \mathrm{~nm}=0.37538 \mu \mathrm{m}$, and the z-axis resolution was measured to be $0.9168 \mu \mathrm{m}$. For $760 \mathrm{~nm}$ excitation, the exposure time per scan for an individual material is expressed as (focal spot area/pixel area) $\times$ 
$100=4.0776 \mathrm{~ms}$, and the total exposure time $t=4.0776 \mathrm{~ms} \times$ number of scans. A $40 \times$ oil-immersion objective $(N A 1.3)$ was used to collect the signals, and the detection range of the spectrum photometer was 300-695 nm.

Additionally, the calculations of laser power $(\mathrm{mW}$ or $\mathrm{nJ}$ pixel $^{-1}$ ) used on the sample were as follows. For the $40 \times$ oilimmersion objective ( $N A 1.3$ ), the transmission rate at $760 \mathrm{~nm}$ in wavelength is approximately $88 \%$ in this optical system, and the laser power went from the output to the objective with only $40 \%$ of the original output power due to the loss of power. As a result, the calculated energy after the objective (on sample) is $P_{\text {output }}(\mathrm{mW}) * 40 \% * 88 \%=0.352 * P_{\text {output }}(\mathrm{mW})$. For instance, $P_{\text {output }}=2.8 \mathrm{~mW}$, the calculated energy after the objective (on the sample) is $2.8 \mathrm{~mW}^{*} 40 \% * 88 \%=0.9856 \mathrm{~mW}$. With $10 \mathrm{kHz}$ of scan rate (each pulse stays $0.1 \mathrm{~ms} \mathrm{pixel}^{-1}$ ), the calculated energy on the sample $\left(\mathrm{J} \mathrm{pixel}^{-1}\right)$ was approximately $P_{\text {output }}(\mathrm{mW}) * 40 \% * 88 \% * 0.1 \mathrm{~ms}=0.0352 * P_{\text {output }}\left(\mathrm{J}\right.$ pixel $\left.^{-1}\right)$. For instance, $P_{\text {output }}=2.8 \mathrm{~mW}$, the energy $\left(\mathrm{J}_{\text {pixel }}{ }^{-1}\right)$ on sample $=2.8 \mathrm{~mW}^{*} 40 \% * 88 \% * 0.1 \mathrm{~ms}=0.09856 \mu \mathrm{J}$ pixel $^{-1}=$ $98.56 \mathrm{~nJ} \mathrm{pixel}^{-1}$. The power after the objective (on the sample) was used and marked throughput this manuscript.

\section{Measurement of TPE Absolute Cross Section ${ }^{9,14,23,25-35}$}

The absolute cross section of TPE was measured the luminescence signal via femtosecond laser optical system according to previous studies. The TPL of fluorescein and rhodamine B (Sigma-Aldrich, St. Louis, MO, USA) had to be verified. The results were obtained by measuring the dependence of the emission intensity with an excitation power range of $704 \mathrm{~nJ}$ pixel $^{-1}(7.04 \mathrm{~mW})$ to $2816 \mathrm{~nJ}$ pixel $^{-1}$ (28.16 $\mathrm{mW})$. Quadratic dependence with the exponents of 2.01 for fluorescein and 2.02 for rhodamine B was measured for increasing the excitation power to determine the luminescence from TPE. According to previous studies, the action cross sections of TPE for fluorescein and rhodamine B are 36.4 and $68.0 \mathrm{GM}\left(1 \mathrm{GM}=10^{-50} \mathrm{~cm}^{4} \mathrm{~s}_{\text {photon }}{ }^{-1}\right)$, respectively, for $760 \mathrm{~nm}$ excitation. We also referred to the free website http://www.drbio.cornell.edu/cross_sections.html, kindly provided by Prof. Chris Xu (Cornell University, NY, USA). The TPE action cross sections for fluorescein and rhodamine B were calculated to be 37.9 and $65.3 \mathrm{GM}$, respectively, which indicated an error of less than 5\% compared with those from Prof. Xu's laboratory. In this study, rhodamine B was chosen as the standard reference for determining the cross section, and the calculated absolute cross sections of TPE for the water-soluble $\mathrm{C}_{60}(\mathrm{OH})_{30}$ fullerenol was approximately $1187.5 \mathrm{GM}$. No batch-to-batch variation was observed for the materials in two-photon properties and two-photon photodynamic ability.

\section{Femtosecond Laser Optical System (for Fluorescence Lifetime Imaging Microscopy, FLIM) $)^{26,32}$}

The home-made femtosecond titanium-sapphire (ti-sa) laser optical system (repetition rate of $80 \mathrm{MHz}$; Tsunami, SpectraPhysics, Santa Clara, CA, USA) was used according to the previous studies. The lifetime data and the parameter generated using the triple-exponential equation fitting while monitoring the emission under TPE (Ex: $760 \mathrm{~nm}$ ).

\section{Calculation of Radiative and Nonradiative Decay Rates ${ }^{33}$}

PL QY and lifetime are both major parameters when investigating the emission characteristics of fluorescent dyes in diverse environments. The QY (Q) can be expressed as follows:

$$
Q=\frac{\Gamma}{\Gamma+k}
$$

where $\Gamma$ is the radiative decay rate, and $k$ is the nonradiative decay rate. Fluorescence lifetime is usually defined as the average time required for an electron in the excited state to decay to the ground state. The TPL lifetime $\tau$ can also be relative to the decay rates and is described as follows:

$$
\tau=\frac{1}{\Gamma+k}
$$

Following Equations (2) and (3), the radiative and nonradiative decay rates can be calculated.

\section{ROS Detection ${ }^{14,18-42}$}

Singlet oxygen $\left({ }^{1} \mathrm{O}_{2}\right)$. (a) Material $\left(5 \mu \mathrm{g} \mathrm{mL}^{-1}\right)$ was treated with MRSA $\left(\mathrm{OD}_{600} \sim 0.05\right)$, after which it was subjected to $3 \mathrm{~h}$ of incubation at $37{ }^{\circ} \mathrm{C}$ in darkness. Subsequently, the mixture was exposed to TPE photoexcitation (228.8 nJ pixel $^{-1}, 600$ or 900 scans; Ex: $760 \mathrm{~nm}$ ) and finally mixed with Singlet Oxygen Sensor Green (SOSG) reagent (1 $\mu \mathrm{M}$; Thermo Fisher Scientific, Waltham, MA, USA) (Ex/Em: $488 / 525 \mathrm{~nm}$ ). A fluorescence spectrometer was employed for measurements. For ROS neutralization, the mixture was mixed with $30 \mathrm{ppm}$ of antioxidant $\alpha$-tocopherol/methyl linoleate (Sigma-Aldrich, St. Louis, MO, USA) in darkness and exposed to TPE photoexcitation with the same treatment. (b) Material (5 $\mu \mathrm{g} \mathrm{mL}^{-1}$ ) was treated with MRSA 
$\left(\mathrm{OD}_{600} \sim 0.05\right)$, after which it was subjected to $3 \mathrm{~h}$ of incubation at $37^{\circ} \mathrm{C} 37^{\circ} \mathrm{C}$ in darkness. Subsequently, the mixture was exposed to TPE photoexcitation (228.8 nJ pixel $^{-1}, 600$ or 900 scans; Ex: $760 \mathrm{~nm}$ ) and finally mixed with $10 \mu \mathrm{M}$ of trans-1-(2'-methoxyvinyl)pyrene ( $t$-MVP, Thermo Fisher Scientific, MA, USA)/0.10 M SDS (Sigma-Aldrich, St. Louis, MO, USA) (Ex/Em: 352/465 $\mathrm{nm})$ For ROS neutralization, the mixture was mixed with $30 \mathrm{ppm}$ of antioxidant $\alpha$-tocopherol/methyl linoleate (Sigma-Aldrich, St. Louis, MO, USA) in darkness. Reaction of $t$-MVP with ${ }^{1} \mathrm{O}_{2}$ yields a dioxetane intermediate that fluoresces while it decomposes into 1-pyrenecarboxaldehyde. Furthermore, this highly selective fluorescent probe does not react with other activated oxygen species such as hydroxyl radicals, superoxide, or hydrogen peroxide. A fluorescence spectrometer was employed for measurements. ROS neutralization was conducted with the same as previously described treatment. Superoxide radical anion $\left(\mathrm{O}_{2} \cdot{ }^{-}\right)$. (a) Material $\left(5 \mu \mathrm{g} \mathrm{mL}{ }^{-1}\right)$ was treated with MRSA $\left(\mathrm{OD}_{600} \sim 0.05\right)$, after which it was subjected to $3 \mathrm{~h}$ of incubation at $37{ }^{\circ} \mathrm{C}$ in darkness. Subsequently, the mixture was exposed to TPE photoexcitation $\left(228.8 \mathrm{~nJ}\right.$ pixel $^{-1}, 600$ or 900 scans; Ex: $760 \mathrm{~nm}$ ) and finally mixed with 2, 3-bis (2-methoxy-4-nitro-5-sulfophenyl)-2H-tetrazolium-5-carboxanilide (XTT, $0.45 \mathrm{mM}$; Sigma-Aldrich, St. Louis, MO, USA). The purpose of this material was that it interacted with $\mathrm{O}_{2}$ - and produced XTT-formazan, resulting in strong absorption (470 $\mathrm{nm}$ in wavelength). UV-vis spectrometer was employed to monitor this absorption. For ROS neutralization, the mixture was mixed with $30 \mathrm{ppm}$ of antioxidant $\alpha$-tocopherol/methyl linoleate (Sigma-Aldrich, St. Louis, MO, USA) in darkness and exposed to TPE photoexcitation with the same treatment. (b) Material $\left(5 \mu \mathrm{g} \mathrm{mL}{ }^{-1}\right)$ was treated with MRSA $\left(\mathrm{OD}_{600} \sim 0.05\right)$, after which it was
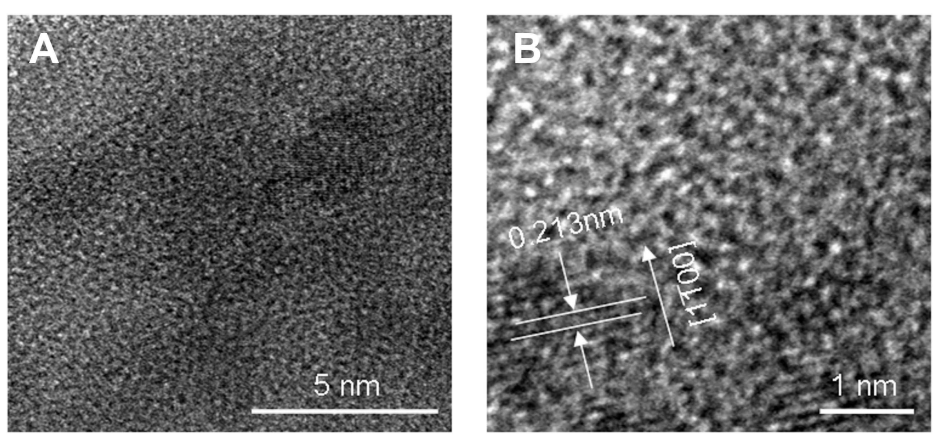

D

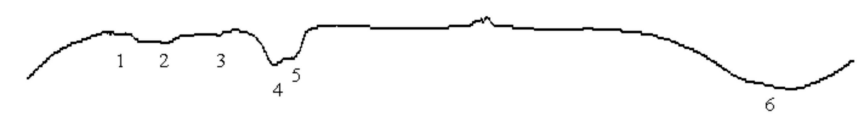

$\begin{array}{lllllllllllllll}800 & 1000 & 1200 & 1400 & 1600 & 1800 & 2000 & 2200 & 2400 & 2600 & 2800 & 3000 & 3200 & 3400 & 3600\end{array}$ Wavenumber $\left(\mathrm{cm}^{-1}\right)$

\begin{tabular}{llll}
\hline Atomic ratio & \multicolumn{3}{c}{ Carbon bonding composition (\%) } \\
\cline { 2 - 4 } $\mathrm{O}(1 \mathrm{~s}) / \mathrm{C}(1 \mathrm{~s})$ & $\mathrm{C}-\mathrm{C} / \mathrm{C}=\mathrm{C}$ & $\mathrm{C}-\mathrm{OH}$ & $\mathrm{C}=\mathrm{O}$ \\
\hline $36.1 \%$ & 33 & 29 & 38 \\
\hline
\end{tabular}
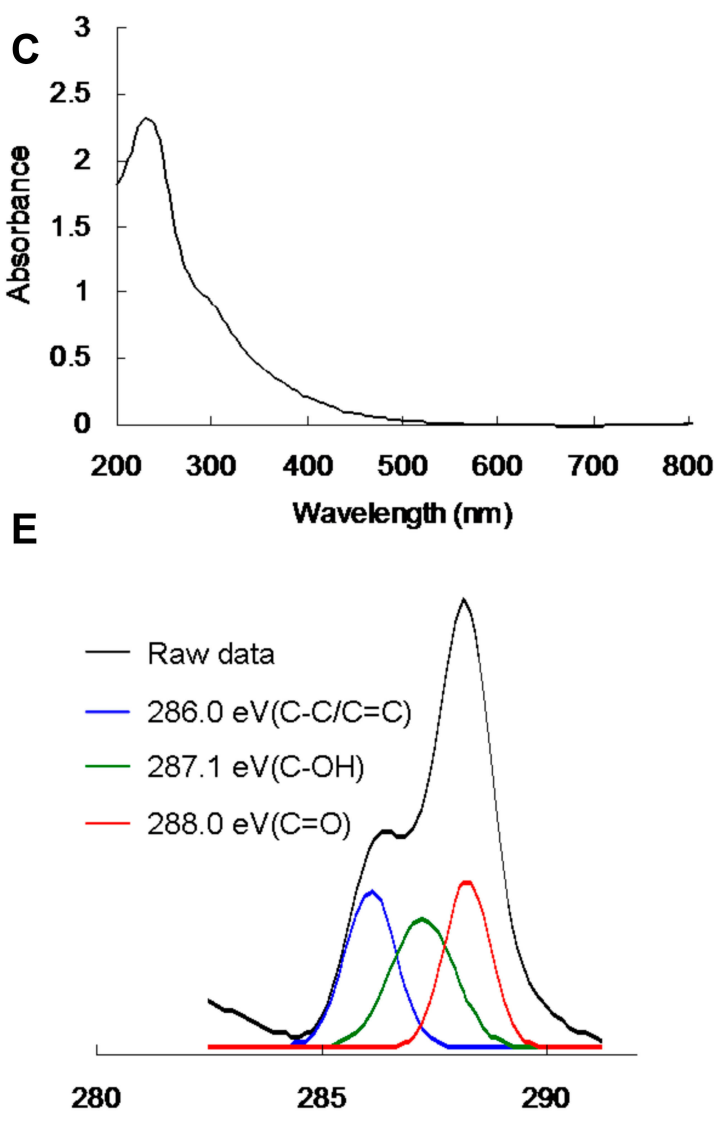

Binding energy (eV)

Figure 2 Functional characterization of synthesized water-soluble $\mathrm{C}_{60}(\mathrm{OH})_{30}$ fullerenol. (A) A low-magnification TEM image reveals that the mean lateral size of water-soluble fullerenol is approximately $1.05 \pm 0.02 \mathrm{~nm}$. (B) HR-TEM image of water-soluble fullerenol illustrating nanomaterials $\{100\}$ lattice planes and a mean size of $1.05 \pm 0.02 \mathrm{~nm}$ with a $\mathrm{d}$-spacing of $0.213 \mathrm{~nm}$. (C) UV-vis spectroscopy. (D) FTIR spectroscopy spectra of fullerenol. (E) Deconvoluted C(Is) XPS spectra and fitted peaks obtained using Gaussian function: nonoxygenated ring $(\mathrm{C}-\mathrm{C} / \mathrm{C}=\mathrm{C}, 286.0 \mathrm{eV}), \mathrm{C}-\mathrm{OH}$ bond $(287 . \mathrm{l} \mathrm{eV})$, and $\mathrm{C}=\mathrm{O}$ bond $(288.0 \mathrm{eV})$, respectively. The atomic ratio and bonding composition of fullerenol are shown in the table. The $\mathrm{O}(\mathrm{Is}) / \mathrm{C}(\mathrm{Is})$ atomic ratio is $36.1 \%$. 
subjected to $3 \mathrm{~h}$ of incubation at $37{ }^{\circ} \mathrm{C}$ in darkness. Subsequently, the mixture was exposed to TPE photoexcitation (228.8 $\mathrm{nJ}$ pixel $^{-1}, 600$ or 900 scans; Ex: $760 \mathrm{~nm}$ ) and finally mixed with $50 \mathrm{mM}$ bicarbonate buffer $(\mathrm{pH} 8.60)$ and glutathione $(\gamma$-L-glutamyl-L-cysteinyl-glycine, $\mathrm{GSH}$; Sigma-Aldrich, St. Louis, MO, USA)/0.80 mM bicarbonate buffer (the Ellman's assay for $\mathrm{O}_{2} \cdot{ }^{-}$detection). Subsequently, the following experiments were conducted according to the procedure in a previous study. Loss of GSH (\%) was calculated as the difference in absorbance between the sample and negative control divided by the absorbance of the negative control. The signal of the generated $\mathrm{O}_{2}{ }^{-}{ }^{-}$was obtained as described in the previous calculation. Data are means $\pm \operatorname{SD}(n=6)$.

\section{Uptake Assay}

MRSA $\left(\mathrm{OD}_{600} \sim 0.05\right)$ was incubated with $5 \mu \mathrm{g} \mathrm{mL} \mathrm{m}^{-1}$ material. The absorbance of a quantity of $5 \mu \mathrm{g} \mathrm{mL} \mathrm{m}^{-1}$ material was recorded by UV-vis spectroscopy (Abs: approximately $203 \mathrm{~nm}$ ). The materials were mixed with MRSA $\left(\mathrm{OD}_{600} \sim 0.05\right)$ at $37{ }^{\circ} \mathrm{C}$ from 1 st $\mathrm{h}$ to 8 th $\mathrm{h}$, respectively, centrifuge (1200 rpm) to remove excess materials, and keep the supernatant and measure its absorbance. The difference in absorbance between the collected supernatant and the original materials was estimated, resulting in the percentage of uptake at each time point. Data are means $\pm \operatorname{SD}(n=6)$.

\section{Statistical Analysis ${ }^{43}$}

The statistical significance was by the analysis of variance. The $p$-value was considered statistically significant for all the treatments.

\section{Results and Discussion Characterization of Water-Soluble Fullerenol}

An illustrative graph of water-soluble $\mathrm{C}_{60}(\mathrm{OH})_{30}$ fullerenol (Figure 1B) was created according to another study, ${ }^{15}$ and the mean lateral size of fullerenol was approximately $1.05 \pm 0.02$ $\mathrm{nm}$, with a typical circular-like shape for aqueous dispersions, as determined through low magnification (Figure 2A)
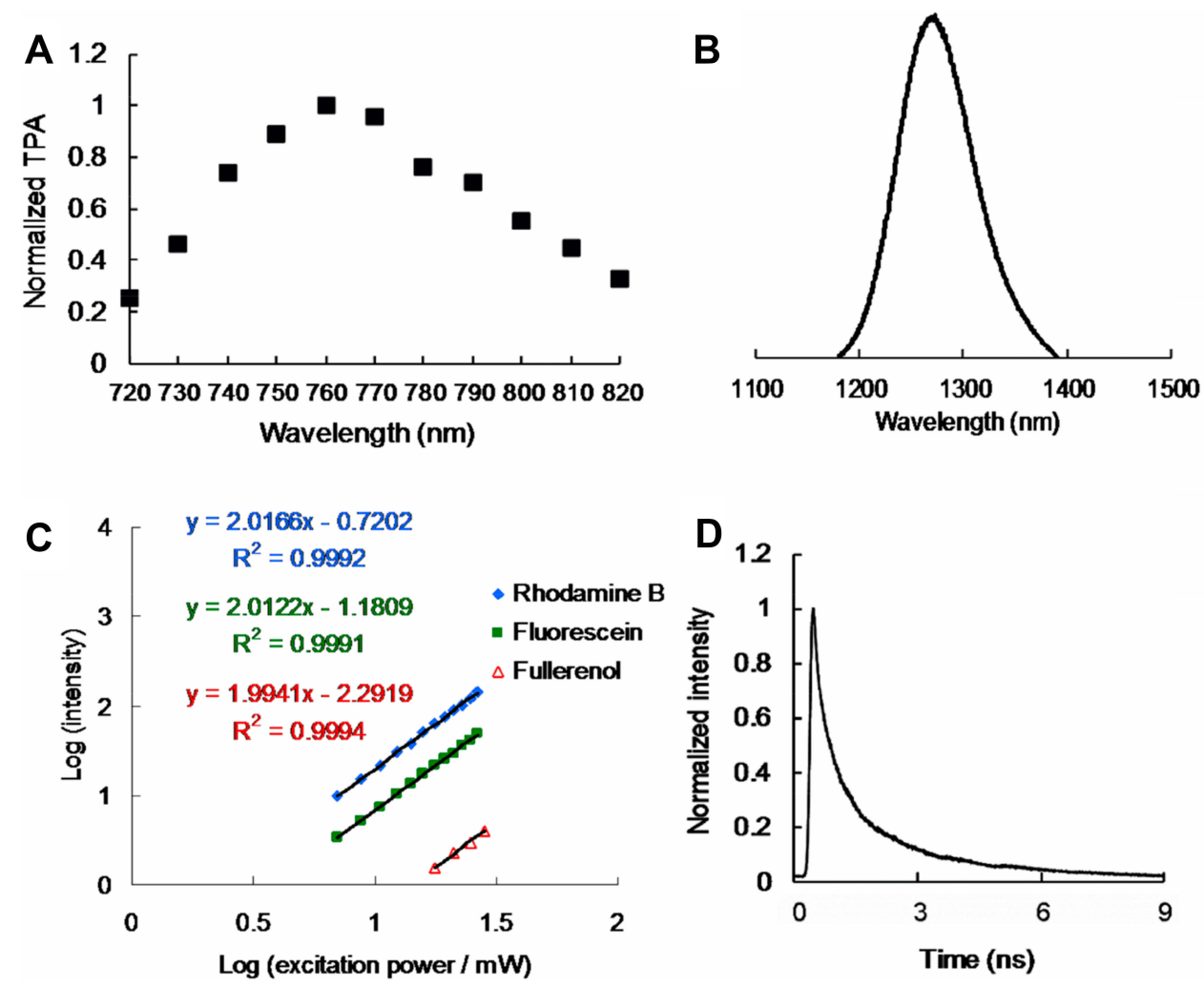

Figure 3 (A) Relative TPA spectra of the material. TPE was used as a function of the wavelength (720-820 nm) at $98.56 \mathrm{~nJ}$ pixel ${ }^{-1}$ to monitor the signals. (B) Measurement of phosphorescence spectra at $1270 \mathrm{~nm}$ for material. (C) Dependence of TPL intensity on excitation power (logarithm) of the materials and fluorophores; TPE exposure

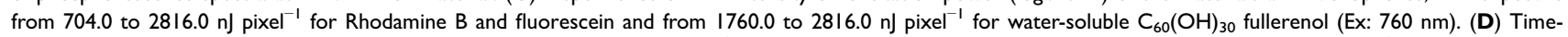
resolved room-temperature PL decay profiles of the material $\left(98.56 \mathrm{~nJ}\right.$ pixel ${ }^{-1}$; Ex: $\left.760 \mathrm{~nm}\right)$. Delivered dose: OD600 of 0.05 of $\mathrm{MRSA}$ and $5 \mu \mathrm{g} \mathrm{mL}^{-1} \mathrm{water}^{-\mathrm{soluble} \mathrm{C}_{60}}$ $(\mathrm{OH})_{30}$ fullerenol. Data are mean \pm SD $(n=6)$. 
and highly magnified HR-TEM (Figure 2B). Favorable crystallinity and lattice distance were also determined to correspond to $d$-spacing of fullerenol $\{100\}$ lattice fringes. However, the materials could aggregate by hydrogen bonds in an aqueous solution of $\mathrm{pH} 7$ with an average size of approximately $130 \mathrm{~nm}$ through dynamic light scattering (Supplementary Information, Table S1). The UV-vis spectroscopy absorption spectrum of fullerenols had no light absorption peaks and may be characterized by consequent strengthening of light absorption with longer wavelengths $(>600 \mathrm{~nm})$. The absorbance occurred at approximately 211 $\mathrm{nm}$, which corresponded to the $\pi-\pi^{*}$ transition of aromatic $\mathrm{C}=\mathrm{C}$ bonds, and at $310 \mathrm{~nm}$, which corresponded to the $\mathrm{n}-\pi^{*}$ transition of aromatic $\mathrm{C}=\mathrm{O}$ shoulder, indicating the existence of $\mathrm{C}_{60}$ (Figure 2C). Further characterizations of the as-prepared materials were performed using FTIR, XPS, and FD mass spectrometry. The characteristic bands of the nanomaterials such as $\mathrm{C}-\mathrm{O}$ (band 1, approximately $1113 \mathrm{~cm}^{-1}$ ); phenolic $\mathrm{C}-\mathrm{OH}$ (band 2, approximately $1261 \mathrm{~cm}^{-1}$ ); tertiary alcoholic $\mathrm{C}-\mathrm{OH}$ (band 3, approximately $1432 \mathrm{~cm}^{-1}$ ); $\mathrm{C}=\mathrm{C}$ ring (band 4, approximately $1660 \mathrm{~cm}^{-1}$ ); $\mathrm{C}=\mathrm{O}$ ring (band 5 , approximately $1733 \mathrm{~cm}^{-1}$ ); $\mathrm{C}-\mathrm{H}$, intermolecular hydrogen bonded, and carboxylate $\mathrm{O}-\mathrm{H}$ (band 6, approximately $3238 \mathrm{~cm}^{-1}$ ); and the band of $\mathrm{CO}_{2}$ interference revealed the aromatic $\mathrm{C}=\mathrm{C}$ bonds and exposed hydroxyl and carbonyl functional groups through FTIR (Figure 2D). The deconvoluted $\mathrm{C}(1 \mathrm{~s})$ spectra of fullerenols indicated a nonoxygenated $\mathrm{C}-\mathrm{C} / \mathrm{C}=\mathrm{C}$ bond $(286.0 \mathrm{eV}), \mathrm{C}-\mathrm{O}$ bond $(287.1 \mathrm{eV}), \mathrm{C}=\mathrm{O}$ bond $(288.0 \mathrm{eV})$, and $\mathrm{O}(1 \mathrm{~s}) / \mathrm{C}(1 \mathrm{~s})$ ratio of approximately $36.1 \%$, examined through XPS (Figure 2E). The atomic ratios and bonding compositions of water-soluble $\mathrm{C}_{60}$ $(\mathrm{OH})_{30}$ fullerenol are summarized in the table provided in Figure 2. Furthermore, the molecular weight of fullerenol was determined using a FD mass spectrometer, and the number of hydroxyl groups was confirmed to be 30 (Supplementary Information, Figure S1), which was consistent with the atomic ratios and bonding compositions of the fullerenol summarized in Figure 2. The aforementioned

Table I Amount of ROS Generated ${ }^{18,19,36-42}$ by Conducting TPE (228.8 nJ Pixel ${ }^{-1}, 600$ or 900 Scans; Ex: $\left.760 \mathrm{~nm}\right)$ and by Using

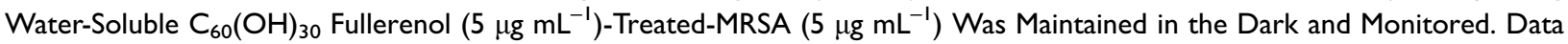
are Mean \pm SD $(n=6)$

\begin{tabular}{|c|c|c|c|c|c|}
\hline & \multirow[b]{2}{*}{ Negative Control $^{\text {ac }}$} & \multicolumn{2}{|l|}{${ }^{\prime} O_{2}$ (by SOSG) ${ }^{c}$} & \multirow[b]{2}{*}{$\mathrm{C}_{60}(\mathrm{OH})_{30}$} & \multirow[b]{2}{*}{ ROS Neutralization ${ }^{\text {bc }}$} \\
\hline & & ROS Neutralization ${ }^{\text {abc }}$ & Positive Control $^{\text {cd }}$ & & \\
\hline 600 scans & $229 \pm 10$ & $230 \pm 11$ & $2606 \pm 122$ & $2304 \pm 118$ & $231 \pm 12$ \\
\hline \multirow[t]{3}{*}{900 scans } & $230 \pm 12$ & $231 \pm 10$ & $284 I \pm 135$ & $2589 \pm 120$ & $23 I \pm 11$ \\
\hline & & \multicolumn{2}{|l|}{${ }^{1} \mathrm{O}_{2}(\text { by } t-M V P)^{\mathrm{e}}$} & \multirow[b]{2}{*}{$\mathrm{C}_{60}(\mathrm{OH})_{30}$} & \multirow[b]{2}{*}{ ROS neutralization ${ }^{\text {be }}$} \\
\hline & Negative control ${ }^{\text {ae }}$ & ROS neutralization ${ }^{\text {abe }}$ & Positive control ${ }^{\text {de }}$ & & \\
\hline \multirow{4}{*}{$\begin{array}{l}600 \text { scans } \\
900 \text { scans }\end{array}$} & $342 \pm 21$ & $343 \pm 23$ & $9398 \pm 238$ & $8582 \pm 191$ & $342 \pm 20$ \\
\hline & $34 I \pm 22$ & $34 I \pm 23$ & $9562 \pm 246$ & $8847 \pm 202$ & $342 \pm 19$ \\
\hline & & $\mathrm{O}_{2}^{\cdot--}(\text { by XTT })^{f}$ & & \multirow[b]{2}{*}{$\mathrm{C}_{60}(\mathrm{OH})_{30}$} & \multirow[b]{2}{*}{ ROS neutralization ${ }^{\text {bf }}$} \\
\hline & Negative control ${ }^{\text {af }}$ & ROS neutralization ${ }^{\text {abf }}$ & Positive control $^{\mathrm{df}}$ & & \\
\hline 600 scans & 0 & 0 & $1.90 \pm 0.13$ & $1.79 \pm 0.10$ & $0.02 \pm 0.01$ \\
\hline \multirow[t]{3}{*}{900 scans } & 0 & 0 & $2.04 \pm 0.20$ & $1.88 \pm 0.16$ & $0.03 \pm 0.01$ \\
\hline & & \multicolumn{2}{|l|}{$\mathrm{O}_{2} \cdot-{ }^{--}$by GSH $)^{g}$} & \multirow[b]{2}{*}{$\mathrm{C}_{60}(\mathrm{OH})_{30}$} & \multirow[b]{2}{*}{ ROS neutralization ${ }^{\text {bg }}$} \\
\hline & Negative control ${ }^{\mathrm{ag}}$ & ROS neutralization ${ }^{\text {abg }}$ & Positive control $^{\mathrm{dg}}$ & & \\
\hline 600 scans & 0 & 0 & $93.8 \pm 3.2 \%$ & $79.5 \pm 1.5 \%$ & $0.2 \pm 0.1 \%$ \\
\hline 900 scans & 0 & 0 & $99.1 \pm 4.4 \%$ & $85.2 \pm 2.6 \%$ & $0.2 \pm 0.1 \%$ \\
\hline
\end{tabular}

Notes: ${ }^{a}$ Negative control: only treat reagent and laser radiation without material $\left(0 \mu \mathrm{g} \mathrm{mL}{ }^{-1}\right)$. ${ }^{\mathrm{b}} \mathrm{ROS}$ neutralization: with the treatments of nanomaterial, the laser irradiation and $30 \mathrm{ppm}$ of antioxidant $\alpha$-Tocopherol/methyl linoleate. ${ }^{\mathrm{C}} \mathrm{SOSG}$ reagent (Ex/Em: 488/525 nm) has a specific reactivity to generate fluorescence recorded by a PL spectrometer. ${ }^{d}$ Positive control: the treatment of $50 \mu \mathrm{M}$ TBHP and laser irradiation. ${ }^{\mathrm{e}} t-\mathrm{MVP}$ (Ex/Em: $352 / 465 \mathrm{~nm}$ ) can react with ${ }^{\mathrm{O}} \mathrm{O}_{2}$, forming a dioxetane intermediate that generates fluorescence upon decomposition to I-pyrenecarboxaldehyde, and monitored by a PL spectrometer. ${ }^{\mathrm{f}} \mathrm{XTT}$ would interact with $\mathrm{O}_{2}{ }^{-}{ }^{-}$and produce the XTT-formazan generating strong absorption (470 nm in wavelength). ${ }^{\mathrm{g}} \mathrm{GSH}$ containing a thiol-tripeptide can prevent damages to cellular or bacterial components caused by stress of oxidation. Thiol group from GSH can be oxidized to disulfide bond converting GSH to glutathione disulfide. GSH oxidation was used to determine the generated $\mathrm{O}_{2}{ }^{-}$. Loss of $\mathrm{GSH}(\%)=$ (absorbance difference between sample and negative control/absorbance of negative control) $\times 100 \%$. 


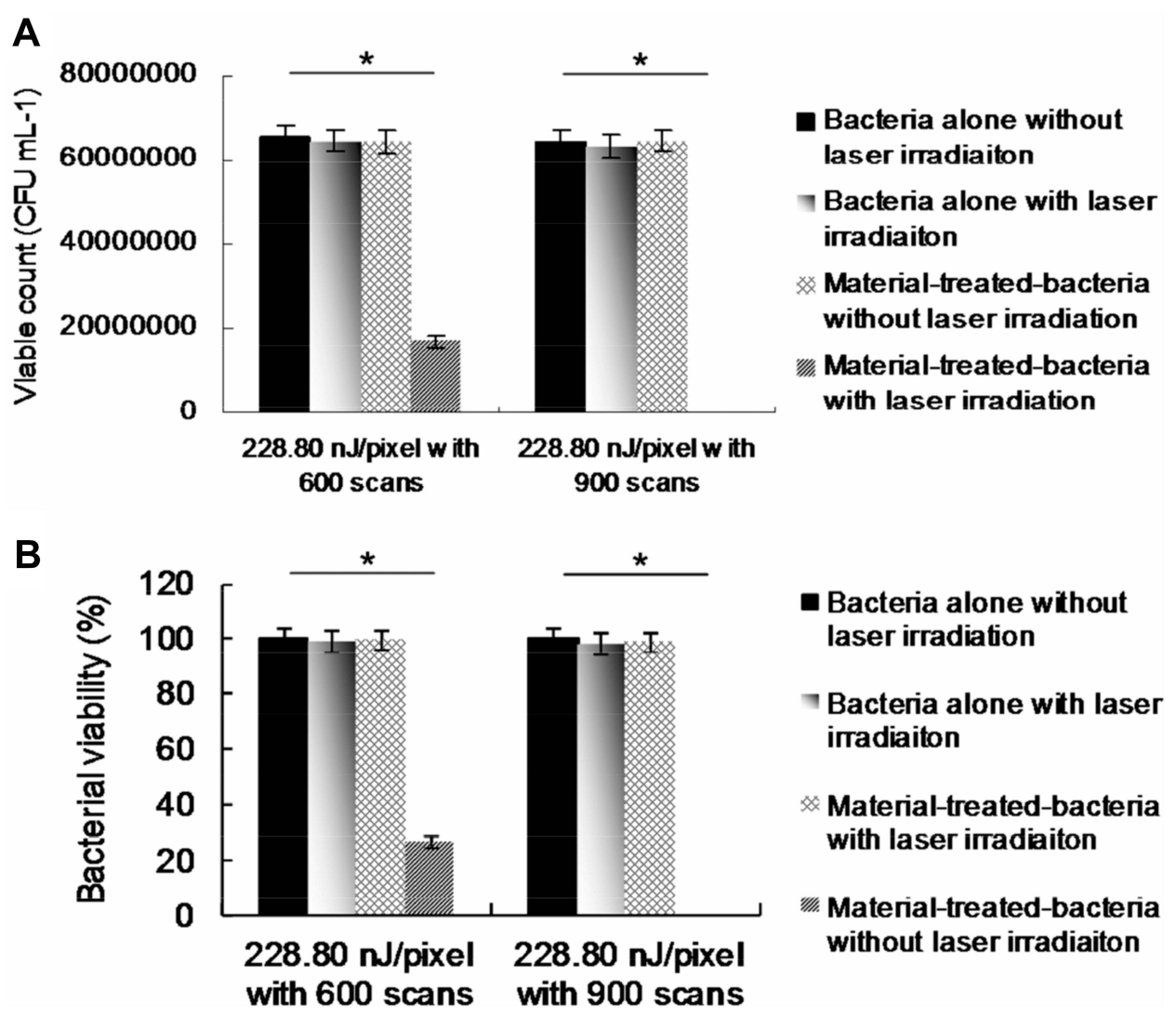

Figure 4 (A, B) Viability (\%) was quantified following the determination of the viable number of material-treated bacteria by using the CFU assay at a TPE power of 228.80 nJ pixel ${ }^{-1}$ with 600 and 900 scans (total effective exposure times of approximately $2.4466 \mathrm{~s}$ and $3.6698 \mathrm{~s}$, respectively; Ex: $760 \mathrm{~nm}$ ). For 600 and 900 scans, $p=0.0742$ and $p$ $<0.000$ I, respectively. The $p$ value was obtained using Student's $t$ test. Delivered dose: $\mathrm{OD}_{600}$ of 0.05 of $\mathrm{MRSA}$ and $5 \mu \mathrm{g} \mathrm{mL} \mathrm{L}^{-1}$ water-soluble $\mathrm{C}_{60}(\mathrm{OH})_{30}$ fullerenol. Data are mean $\pm S D(n=6)$.

characterizations confirmed that fullerenols had been successfully synthesized.

\section{ROS Generation of Water-Soluble Fullerenol Through TPE}

A gram-positive MRSA strain was used as the experimental template in this study. Viability was determined using the CFU counting assay (Supplementary Information, Figure S2a), the results of which are expressed as percentages corresponding to CFU $\mathrm{mL}^{-1}$ (Supplementary Information, Figure S2b). The results revealed an approximately $0 \log _{10}$ reduction corresponding to nearly $100 \%$ viability because $\mathrm{C}_{60}(\mathrm{OH})_{30}$ exhibited favorable biocompatibility; the material also exhibited excellent stability in physiological environments, eg, aqueous solution of $\mathrm{pH} 7,1 \times \mathrm{PBS}$, and culture medium of MRSA (Supplementary Information, Table S1). To prevent the possibility of confounding following ROS generation or PDT, water-soluble $\mathrm{C}_{60}(\mathrm{OH})_{30}$ was inadvertently exposed to white light, which could lead to the experiment being compromised. On the basis of the results, a low dose $\left(5 \mu \mathrm{g} \mathrm{mL} \mathrm{m}^{-1}\right)$ of treated $\mathrm{C}_{60}(\mathrm{OH})_{30}$ was incubated with MRSA $\left(\mathrm{OD}_{600}\right.$ of approximately 0.05 ) at $37^{\circ} \mathrm{C}$ for $3 \mathrm{~h}$ in the dark and was used in all of the following two-photon photochemistry-related experiments. In addition, for investigating the antimicrobial ability of water-soluble $\mathrm{C}_{60}(\mathrm{OH})_{30}$ fullerenol in ROS generation or PDT through TPE, materials with excellent TPA at 760 $\mathrm{nm}$ in the near-infrared (NIR) region were used (Figure 3A), probably because of the interband transitions involved. ${ }^{44}$ Oxidative stress of ROS contributing to the failure of biological substrates surrounding the photoexcited fullerenol-treated MRSA would inhibit redox reactions and result in DNA damage and eventually bacterial death. Therefore, the major

Table 2 Two-Photon Action Cross Sections of Fluorescein (in $0.1 \mathrm{M} \mathrm{NaOH}, \mathrm{pH}$ I I) and Rhodamine B (in Methanol). Excitation Wavelength: $760 \mathrm{~nm}$

\begin{tabular}{|l|l|l|}
\hline Excitation wavelength at $760 \mathrm{~nm}$ & Fluorescein (in & Rhodamine $\mathrm{B}$ \\
action cross section, $\eta \sigma_{2}(\mathrm{GM}$, & $\mathrm{ddH}_{2} \mathrm{O}$, & (in \\
$10^{-50} \mathrm{~cm}^{4} \mathrm{~s} /$ photon) & $\mathrm{pH}=\mathrm{II}$ ) & methoanol) \\
& 37.9 & 65.3 \\
\hline
\end{tabular}


Table 3 TPE Cross Section of Materials (Ex: $760 \mathrm{Nm})^{\mathrm{a}}$

\begin{tabular}{|c|c|c|c|}
\hline Reference & $\begin{array}{l}\text { Integrated } \\
\text { Emission } \\
\text { Intensity } \\
\text { (Counts) }\end{array}$ & & $\begin{array}{l}\text { Action } \\
\text { Cross- } \\
\text { Section } \\
(\eta \sigma)\end{array}$ \\
\hline Rhodamine B & 271.45 & & 65.3 \\
\hline Sample & $\begin{array}{l}\text { Integrated emission } \\
\text { intensity (counts) }\end{array}$ & $\begin{array}{l}\text { Relative } \\
\text { quantum } \\
\text { yield }(\eta)\end{array}$ & $\begin{array}{l}\text { Absolute } \\
\text { cross- } \\
\text { section }(\sigma)\end{array}$ \\
\hline $\begin{array}{l}\text { Water-soluble } \\
\mathrm{C}_{60}(\mathrm{OH})_{30} \\
\text { fullerenol }\end{array}$ & 246.82 & 0.05 & 1187.50 \\
\hline
\end{tabular}

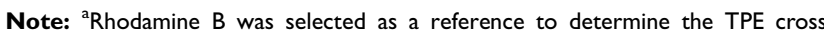
section. (Information was obtained from the free website http://www.drbio.cornell. edu/cross_sections.html, kindly provided by Prof. Chris Xu, Cornell University, NY, USA), and the relevant calculations were shown in Materials and Methods.

roles of ${ }^{1} \mathrm{O}_{2}$ and $\mathrm{O}_{2}{ }^{-}$. from the generated ROS mainly involved in PDT through TPE (228.80 nJ pixel ${ }^{-1}$ with 600 or 900 scans; Ex: $760 \mathrm{~nm}$ ) were monitored. The intensity of ${ }^{1} \mathrm{O}_{2}$ was measured by monitoring fluorescence intensities from a SOSG reagent and $t$-MVP; $\mathrm{O}_{2}{ }^{-}$intensity was detected based on the absorbance of XTT at $470 \mathrm{~nm}$, and GSH after interaction with materials, ${ }^{18,19,36-42}$ and the quantities of ${ }^{1} \mathrm{O}_{2}$ and $\mathrm{O}_{2}$. ${ }^{-}$generated are presented in Table S2 (Supplementary Information). The results are attributed to ROS generated from the twophoton photosensitization of water-soluble $\mathrm{C}_{60}(\mathrm{OH})_{30}$. To confirm the involvement of ROS in the PDT effect of the material, $\alpha$-tocopherol was used for ROS neutralization. ${ }^{37}$ The amount of generated ROS was reduced after adding $\alpha$-tocopherol. Considering that false-positive signals of ROS might have resulted from interactions between materials and ROS reagents (SOSG, $t$-MVP, XTT, and GSH) ${ }^{18,19,36-42}$ and might have led to compromised results, another detection method was used to measure and monitor ROS formed by the laser-irradiated material-treated bacteria (Table 1); ROS presented a trend similar to that in Table S2 (Supplementary Information), consistent with the signal of ${ }^{1} \mathrm{O}_{2}$ phosphorescence at $1270 \mathrm{~nm}$ emitted from materials (Figure 3B).

\section{Determination of Antimicrobial Ability} with TPE

In PDT through TPE (228.80 $\mathrm{nJ}$ pixel $\left.^{-1}\right)$, bacteria were treated with the material according to different numbers of photoexcitation scans (600-900 scans). The results indicated no bactericidal effects on MRSA alone, with or without laser exposure, and no bactericidal effects on the panel of material-treated bacteria without laser treatment (Figure 4A and B). However, $\mathrm{C}_{60}(\mathrm{OH})_{30}$ efficiently exerted antibacterial effects, and the viability of bacteria began to decrease after 600 scans (Figure 4A and B). A total of $26 \%$ viability, corresponding to approximately $0.585 \log _{10}$ reduction of material-treated bacteria, was observed after exposure. Over time, the viability of bacteria was reduced to the point of $100 \%$ elimination (approximately $7.816 \log _{10}$ reduction) of the bacteria after the same procedure with 900 scans. However, irrespective of the method used, water-soluble fullerenols exhibited excellent ability to form ROS, and the singlet oxygen QY $\left(\psi_{\Delta}\right)$ was measured at approximately $0.89\left(\psi_{\Delta}=0.64\right)$ of TSPP dissolved in $\mathrm{D}_{2} \mathrm{O}$ as a reference. ${ }^{16}$ Moreover, the calculated fluorescence QY value of water-soluble $\mathrm{C}_{60}(\mathrm{OH})_{30}$ was relatively low, at approximately $0.05\left(\mathrm{QY}_{\mathrm{ref}}=0.280\right.$ for Cy5.5 dissolved in DMSO as a reference ${ }^{20}$ ), and one photon exhibited the same QY value. ${ }^{18,19}$ The hydroxyl group on the surface of fullerenols induces nonradiative recombination of electron-hole pairs, inhibiting intrinsic state emission. According to the QYs, the aforementioned results, and the Aleksander Jablonski diagram, ${ }^{45}$ first excited singlet-state electron change was mainly through the pathway of intersystem crossing instead of fluorescence generation, leading to a relatively strong interaction of the excited triplet state electron with the oxygen and thus the generation of singlet oxygen for processing PDT.

\section{Investigation of Two-Photon Property}

For the nonlinear laser process, TPE can maintain low average laser power and enable the excited wavelength to be extended to the NIR window, thus improving the visibility of the twophoton processes. However, to monitor molecular actions, a

Table 4 The Lifetime Data and the Parameter Generated Using a Time-Correlated Single-Photon Counting Technique Involving a Triple-Exponential Fitting Function While Monitoring the Emission with $760 \mathrm{~nm}$ of Wavelength Under TPE

\begin{tabular}{|l|l|l|l|l|l|l|l|l|l|l|}
\hline \multicolumn{3}{|c|}{3 Exp Fitting Model: (a0*exp(alx)+a2*exp(a3x)+a4*exp(a5x)+a6) } & Lifetimel & Lifetime2 & Lifetime3 & $\begin{array}{l}\text { Average Lifetime } \\
\text { (ns) }\end{array}$ \\
\cline { 1 - 8 } & a0 & al & a2 & a3 & a4 & a5 & a6 & & & \\
\hline 329.915 & -1.50745 & 852.165 & -0.43564 & 417.301 & -0.04941 & -177.295 & 0.663372 & 2.295489 & 20.23845 & 6.640392141 \\
\hline
\end{tabular}

Note: ${ }^{a}$ The parameters were obtained from the iterative reconvolution of the decay with the instrument response function. 
large cross-section is desirable. With high QY and TPE crosssections, intrinsic possession of fluorophores and enhancement of localized excitation power can increase two-photon properties. ${ }^{26}$ The TPL of reference fluorophores, rhodamine $\mathrm{B}$, and fluorescein was verified. In a two-photon process with exponents of 2.02 and 2.01 for rhodamine B and fluorescein, respectively (Figure 3C), PL intensity demonstrated a quadratic dependence on the excitation power of TPE at a wavelength of $760 \mathrm{~nm}^{30,46}$ and also detected and demonstrated an excitation power of 1.99 for water-soluble $\mathrm{C}_{60}(\mathrm{OH})_{30}$ under TPE, even though the value of the fluorescence QY was relatively low. Based on the Materials and Methods for calculation, TPE action cross-sections for fluorescein and rhodamine B were calculated to be 37.9 and 65.3 Goeppert-Mayer units (GM, $1 \mathrm{GM}=10^{-50} \mathrm{~cm}^{4} \mathrm{~s}$ photon ${ }^{-1}$ ), respectively (Table 2). High values of the absolute cross-section of TPE render fluorophores effective for investigation because these values correspond to a high ratio of energy absorbed into input energy flux in a specimen, and higher ratios correspond to a lower probability of photodamage. A large cross-section is desirable for monitoring molecular activities in vitro or in vivo through two-photon techniques. ${ }^{18,19,36}$ The calculated absolute cross-section of TPE for water-soluble $\mathrm{C}_{60}(\mathrm{OH})_{30}$ was approximately $1187.50 \mathrm{GM}$ (Rhodamine $\mathrm{B}$ was selected as the standard reference ${ }^{9}$ for determining the cross-section; Figure $3 \mathrm{C}$ and Table 3), which was similar to that in other studies. ${ }^{27,47}$ After further investigation, lifetime was also measured; sequentially, the effects of radiative and nonradiative decay rates on $\mathrm{QY}$ and lifetime were calculated. The average lifetime of water-soluble $\mathrm{C}_{60}(\mathrm{OH})_{30}$ was approximately 6.640 ns, which was calculated from observed lifetimes of 0.6634 , 2.2955, and 20.2385 ns (Figure 3D and Table 4). Therefore, the ratio of radiative to nonradiative decay rates of the material was approximately 0.053 (derived from the respective rates of $7.530 \times 10^{6} \mathrm{~s}^{-1}$ and $1.431 \times 10^{8} \mathrm{~s}^{-1}$ ) following Equations (2) and (3). According to the results, this absolute cross-section does not show a superior value to graphene quantum dot-based nanomaterials. ${ }^{18,19,21,22}$ Moreover, water-soluble $\mathrm{C}_{60}(\mathrm{OH})_{30}$ fullerenol primarily passes through the nonradiative pathway instead of the radiative pathway after TPE because of the low fluorescence QY and long lifetime. This is consistent with the hydroxyl group on the surface of well-prepared fullerenols in this study, which induced nonradiative recombination of electron-hole pairs, thereby inhibiting intrinsic state emission.
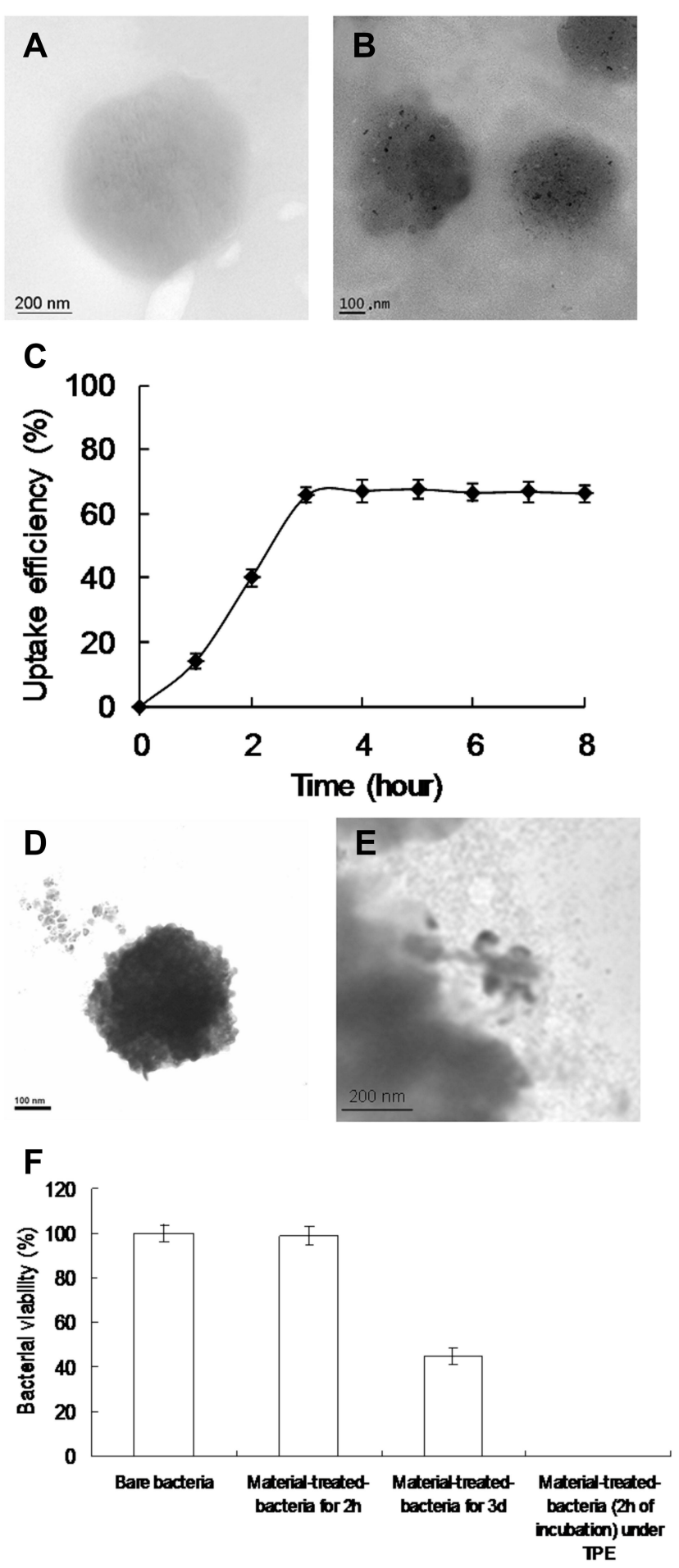

Figure 5 TEM images. (A) MRSA without any treatment. Bacteria treated with material for (B) $2 \mathrm{~h}$ and (D) 3 days of incubation. (E) The photoexcited materialtreated bacteria $\left(2 \mathrm{~h}\right.$ of incubation) with TPE (228.8 nJ pixel ${ }^{-1}, 900$ scans; Ex: $760 \mathrm{~nm}$ ). (C) Uptake assay of MRSA and materials at $37^{\circ} \mathrm{C}$. (F) Viability (\%) was quantified following the determined viable count of material-treated bacteria using the CFU assay by short excitation with the same treatment. Delivered dose: $\mathrm{OD}_{600}$ of 0.05 of MRSA and $5 \mu \mathrm{g} \mathrm{mL}^{-1}$ water-soluble $\mathrm{C}_{60}(\mathrm{OH})_{30}$ fullerenol. Data are mean $\pm \mathrm{SD}(\mathrm{n}=6)$ 


\section{TEM Assay to Observe the Water- Soluble Fullerenol-Treated MRSA}

TEM was necessary to determine the effect of fullerenol treatment with TPE on MRSA. Incubation of bare MRSA (Figure 5A) with water-soluble $\mathrm{C}_{60}(\mathrm{OH})_{30}$ fullerenol for $2 \mathrm{~h}$ resulted in a considerable amount of materials being adsorbed on the bacterial surface (Figure 5B). The uptake assay results also revealed the amount of materials adsorbed on the bacterial surface, with a burst rate of approximately $66 \%$ within the first $3 \mathrm{~h}$ of incubation (Figure 5C). The rate achieved a saturated status from 3 to $8 \mathrm{~h}$ of incubation because the sites of material absorption in the cell wall were completely occupied. Bacteria must filter external ions and assimilate nutrients using the cell wall to maintain and develop their physiological functions. ${ }^{48,49}$ Thus, the materials were absorbed and accumulated to form an external barrier on the bacterial surface. The material-treated bacteria demonstrated no exceptional morphology after $2 \mathrm{~h}$ of incubation, whereas an incubation period of 3 days changed the shape of the bacteria (Figure 5D), corresponding to nearly $45 \%$ viability (Figure 5f; Supplementary Information, Figure S3). However, unusual, drastic damage to morphology that corresponded to nearly $100 \%$ death occurred after photoexcitation of the material-treated bacteria $(2 \mathrm{~h}$ of incubation) (Figure 5E). According to the aforementioned results, water-soluble $\mathrm{C}_{60}(\mathrm{OH})_{30}$ is a promising two-photon PS for completely eliminating bacteria. In addition, the viability of surviving MRSA was expressed through fluorescence and quantification (Figure 6). ${ }^{22,49}$ The laser-exposed bacteria alone indicated nearly no damage, as represented by green fluorescence that is indicative of live bacteria (Figure 6A), corresponding to Figure 5A. The dead bacteria were distinguishable to a certain degree regarding the treatment of water-soluble $\mathrm{C}_{60}(\mathrm{OH})_{30}$ and laser exposure (represented by the red fluorescence; Figure 6B), corresponding to Figure 5E. Viability of bacteria was quantified for further antimicrobial tests, which indicated that nearly all of the nanomaterial-treated bacteria were dead after treatment (Figure 6C). Viability was also consistent with the results in Figure $5 \mathrm{~F}$ and Figure $\mathrm{S} 3$ (Supplementary Information) presents the efficient antibacterial effects of water-soluble $\mathrm{C}_{60}$ $(\mathrm{OH})_{30}$ through two-photon PDT.

\section{Conclusion}

Fullerenol is being applied in an increasing number of research fields. However, fullerenol, hydrophilic fullerenol in particular, has not received attention as a PS that can directly generate ROS through TPE. In this study, watersoluble fullerenol-generated ROS were able to execute PDT with a high level of efficacy and thereby eliminate gram-positive bacteria of MRSA at ultra-low energy levels over an extremely short period of photoexcitation through TPE in an NIR window. Water-soluble fullerenol had high TPA, a large absolute cross-section of TPE, and high twophoton stability, making it a promising two-photon PS for performing two-photon PDT through TPE. It constitutes an efficient alternative approach to eliminating MDR bacteria.

\section{Author Contributions}

W.S.K. designed this work, and conducted all of the experiments. P.C.W. conducted all of the experiments
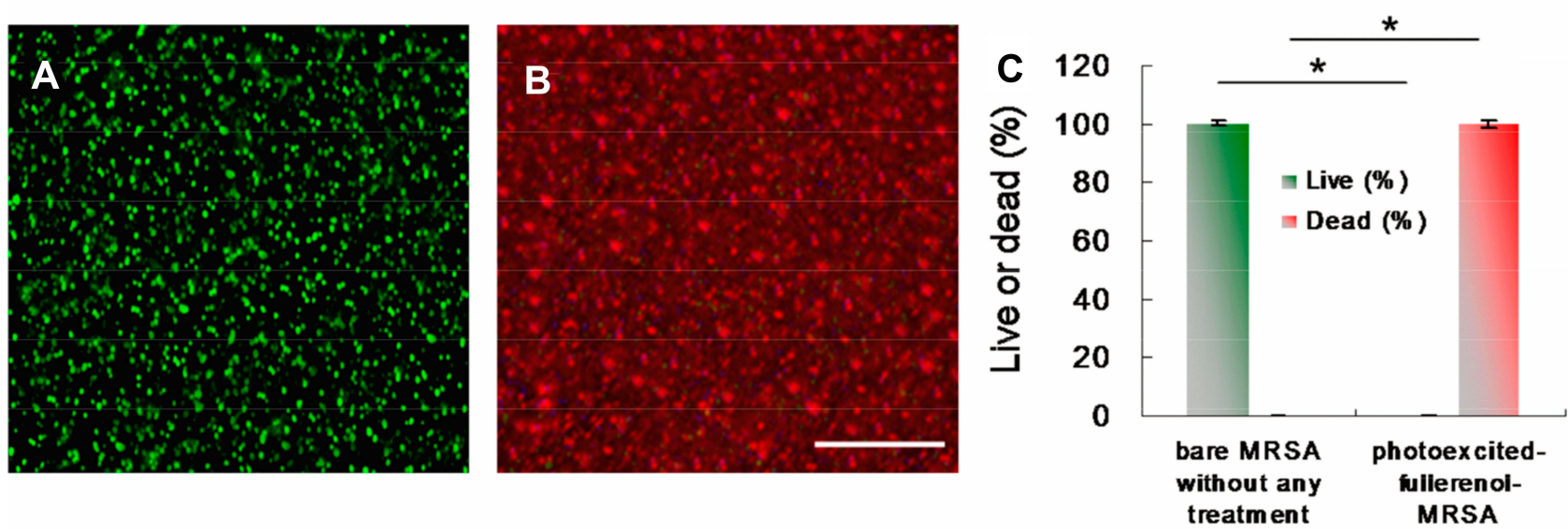

Figure 6 Images and viability of bacteria. After TPE (228.8 nJ pixel, ${ }^{-1} 900$ scans; Ex: $\left.760 \mathrm{~nm}\right)$ of $(\mathbf{A}, \mathbf{B})$ water-soluble $\mathrm{C}_{60}(\mathrm{OH})_{30}$-treated MRSA, a live/dead kit was used to stain bacteria, images were obtained, and $(\mathbf{C})$ viability was quantified. For the live percentage and dead percentage, $p<0.00 \mathrm{I}$. $* p$ value was obtained by Student's $t$-test. $\mathrm{OD}_{600}$ of 0.05 of MRSA and $5 \mu \mathrm{g} \mathrm{mL}{ }^{-1}$ water-soluble $\mathrm{C}_{60}(\mathrm{OH})_{30}$ fullerenol. Data are mean $\pm \mathrm{SD}(\mathrm{n}=6)$. Scale bar: $50 \mu \mathrm{m}$. 
related to materials and biology. C.Y.C. conducted the experiments related to optics \& photonics. J.C.L. assisted and performed the experiments related to biology. J.H.C. and E.C.S. designed this work, and conducted all of the experiments related to biology. All authors contributed to conceptualization, data curation, formal analysis, investigation, methodology, resources, validation and visualization. The original and revised drafts were written through contributions of all authors. All authors have given approval to the final version of the manuscript to be published, and agree to be accountable for all aspects of the work.

\section{Funding}

This work was supported by Research Start-Up Fund of Nanjing University of Information Science \& Technology, China (2018r047), An Nan Hospital, China Medical University, Taiwan (ANHRF107-10), Ministry of Science and Technology, Taiwan (MOST 108-2314-B-006-053-, 1092622-E-006-013-CC3, 109-2636-E-006-018-) and the Center of Applied Nanomedicine and Medical Device Innovation Center (MDIC) at National Cheng Kung University from the Featured Areas Research Center Program within the framework of the Higher Education Sprout Project, Ministry of Education, Taiwan. And thanks to the technical services provided by the i-MANI center of National Core Facility for Biopharmaceuticals, Instrument Development Center, Ministry of Science and Technology, Taiwan.

\section{Disclosure}

There are no conflicts of interest to declare in regard to this work.

\section{References}

1. Konan YN, Gurny R, Allémann E. State of the art in the delivery of photosensitizers for photodynamic therapy. $J$ Photochem Photobiol B. 2002;66:89-106. doi:10.1016/S1011-1344(01)00267-6

2. Dougherty TJ. Photosensitizers: therapy and detection of malignant tumors. Photochem Photobiol. 1987;45:879-889. doi:10.1111/j.17511097.1987.tb07898.x

3. Agostinis P, Berg K, Cengel KA, et al. Photodynamic therapy of cancer: an update. CA Cancer J Clin. 2011;61:250-281. doi:10.3322/caac.20114

4. Li XH, Zheng C, Guyader LL, et al. "Smart" nanomaterials for cancer therapy. Sci China Chem. 2010;53:2241-2249. doi:10.1007/s11426010-4122-9

5. Kroto HW, Heath JR, O'Brien SC, et al. $\mathrm{C}_{60}$ : buckminsterfullerene. Nature. 1985;318:162-163. doi:10.1038/318162a0

6. Montellano A, Ros T, Bianco A, et al. Fullerene $\mathrm{C}_{60}$ as a multifunctional system for drug and gene delivery. Nanoscale. 2011;3:40354041. doi:10.1039/c1nr10783f
7. Nielsen GD, Roursgaard M, Jensen KA, et al. In vivo biology and toxicology of fullerenes and their derivatives. Basic Clin Toxicol. 2008;103:197-208. doi:10.1111/j.1742-7843.2008.00266.x

8. Sharma SK, Chiang LY, Hamblin MR. Photodynamic therapy with fullerenes in vivo: reality or a dream? Nanomedicine. 2011;6:18131825. doi:10.2217/nnm.11.144

9. Xu C, Zipfel W, Shear JB, et al. Multiphoton fluorescence excitation: new spectral windows for biological nonlinear microscopy. Proc Natl Acad Sci USA. 1996;93:10763-10768. doi:10.1073/pnas.93.20.10763

10. Zipfel WR, Williams RM, Webb WW. Nonlinear magic: multiphoton microscopy in the biosciences. Nat Biotechnol. 2003;21:1369-1377. doi:10.1038/nbt899

11. Helmchen F, Denk W. Deep tissue two-photon microscopy. Nat Methods. 2005;2:932-940. doi:10.1038/nmeth818

12. Zharov VP. Ultrasharp nonlinear photothermal and photoacoustic resonances and holes beyond the spectral limit. Nat Photonics. 2011;5:110-116. doi:10.1038/nphoton.2010.280

13. Gao D, Agayan RR, Xu H, et al. Nanoparticles for two-photon photodynamic therapy in living cells. Nano Lett. 2006;56:23832386. doi: $10.1021 / \mathrm{n} 10617179$

14. Liu Q, Guo B, Rao Z, et al. Strong two-photon induced fluorescence from photostable, biocompatible nitrogen-doped graphene quantum dots for cellular and deep-tissue imaging. Nano Lett. 2013;13:24362441. doi:10.1021/n1400368v

15. Chiang LY, Wang LY, Swirczewski JW, et al. Efficient synthesis of polyhydroxylated fullerene derivatives via hydrolysis of polycyclosulfated precursors. J Org Chem. 1994;14:3960-3968. doi:10.1021/jo00093a030

16. Shi L, Hernandez B, Selke M. Singlet oxygen generation from watersoluble quantum dot-organic dye nanocomposites. $\mathrm{J} \mathrm{Am} \mathrm{Chem} \mathrm{Soc.}$ 2006;128:6278-6279. doi:10.1021/ja057959c

17. Davila J, Harriman A. Photoreactions of macrocyclic dyes bound to human serum albumin. Photochem Photobiol. 1990;51:9-19. doi:10.1111/j.1751-1097.1990.tb01678.x

18. Kuo WS, Hsu CLL, Chen HH, et al. Graphene quantum dots conjugated with polymers for two-photon properties under two-photon excitation. Nanoscale. 2016;8:16874-16880. doi:10.1039/C6NR02614A

19. Wu PC, Wang JY, Wang WL, et al. Efficient two-photon luminescence for cellular imaging using biocompatible nitrogen-doped graphene quantum dots conjugated with polymers. Nanoscale. 2018;10:109-117. doi:10.1039/C7NR06836K

20. Umezawa K, Matsui A, Nakamura Y, et al. Bright, color-tunable fluorescent dyes in the vis/NIR region: establishment of new "tailor-made" multicolor fluorophores based on borondipyrromethene. Chem Eur J. 2009;15:1096-1106. doi:10.1002/chem.200801906

21. Kuo WS, Shao YT, Huang KS, et al. Antimicrobial amino-functionalized nitrogen-doped graphene quantum dots for eliminating multidrug-resistant species in dual-modality photodynamic therapy and bioimaging under two-photon excitation. ACS Appl Mater Interfaces. 2018;10:14438-14446. doi:10.1021/acsami.8b01429

22. Kuo WS, Chang CY, Chen HH, et al. Two-photon photoexcited photodynamic therapy and contrast agent with antimicrobial graphene quantum dots. ACS Appl Mater Interfaces. 2016;8:3046730474. doi:10.1021/acsami.6b12014

23. Kuo WS, Lien CH, Cho KC, et al. Multiphoton fabrication of freeform polymer microstructures with gold nanorods. Opt Express. 2010;18:27550-27559. doi:10.1364/OE.18.027550

24. Marsh PN, Burns D, Girkin JM. Practical implementation of adaptive optics in multiphoton microscopy. Opt Express. 2003;11:1123-1130. doi:10.1364/OE.11.001123

25. Cheng LC, Lien CH, Sie YD, et al. Nonlinear structured-illumination enhanced temporal focusing multiphoton excitation microscopy with a digital micromirror device. Biomed Opt Express. 2014;5:25262536. doi:10.1364/BOE.5.002526

26. Albota MA, Xu C, Webb WW. Two-photon fluorescence excitation cross sections of biomolecular probes from 690 to $960 \mathrm{~nm}$. Appl Optics. 1998;37:7352-7356. doi:10.1364/AO.37.007352 
27. Wang M, Nalla V, Jeon S, et al. Larger femtosecond two-photon absorption cross sections of fullerosome vesicle nanostructures derived from a highly photoresponsive amphiphilc C60-light-harvesting fluorine dyad. J Phys Chem C. 2011;115:18552-18559. doi:10.1021/jp207047k

28. Wang H, Huff TB, Zweifel DA, et al. In vitro and in vivo two-photon luminescence imaging of single gold nanorods. Proc Natl Acad Sci USA. 2005;102:15752-15756. doi:10.1073/pnas.0504892102

29. Wu C, Szymanski C, Cain Z, et al. Conjugated polymer dots for multiphoton fluorescence imaging. $J \mathrm{Am}$ Chem Soc. 2007;129:12904-12905. doi:10.1021/ja074590d

30. Park J, Estrada A, Sharp K, et al. Two-photon-induced photoluminescence imaging of tumors using near-infrared excited gold nanoshells. Opt Express. 2008;16:1590-1599. doi:10.1364/OE.16.001590

31. Lapadula G, Bourdole A, Allouche F, et al. Near-IR two photon microscopy imaging of silica nanoparticles functionalized with isolated sensitized $\mathrm{Yb}(\mathrm{III})$ centers. Chem Mater. 2014;26:1062-1073. doi:10.1021/cm404140q

32. Wolfbeis OS. An overview of nanoparticles commonly used in fluorescent bioimaging. Chem Soc Rev. 2015;44(14):4743-4768. doi:10.1039/C4CS00392F

33. Zhou G, Gu M. Direct optical fabrication of three-dimensional photonic crystals in a high refractive index $\mathrm{LiNbO}_{3}$ crystal. Opt Lett. 2006;31:2783-2785. doi:10.1364/OL.31.002783

34. Weber G, Teale FWJ. Determination of the absolute quantum yield of fluorescent solutions. Trans Faraday Soc. 1957;53:646-655. doi:10.1039/tf9575300646

35. Cao L, Wang X, Meziani MJ, et al. Carbon dots for multiphoton bioimaging. J Am Chem Soc. 2007;129:11318-11319. doi:10.1021/ ja0735271

36. Chang WT, Chen SJ, Chang CY, et al. Effect of size-dependence photodestructuve efficacy by gold nanomaterials with multiphoton Laser. ACS Appl Mater Interfaces. 2015;7:17318-17329. doi:10.1021/acsami.5b04431

37. Kinen MM, Kamal-Eldin A, Lampi AM, et al. Effects of $\alpha$ - and $\gamma$ tocopherols on formation of hydroperoxides and two decomposition products from methyl linoleate. J Am Oil Chem Soc. 2000;77:801806. doi:10.1007/s11746-000-0128-z

38. Sharma P, Jha AB, Dubey RS, et al. Reactive oxygen species, oxidative damage, and antioxidative defense mechanism in plants under stressful conditions. J Bot. 2012;2012:1-26. doi:10.1155/ $2012 / 217037$
39. Possel H, Noack H, Augustin W, et al. An oxidant, tert-butyl hydroperoxide (TBHP), to serve as a positive control. FEBS Lett. 1997;416:175-178. doi:10.1016/S0014-5793(97)01197-6

40. Thompson A, Lever JR, Canella KA, et al. Chemiluminescence mechanism and quantum yield of synthetic vinylpyrene analogues of benzo[a]pyrene-7,8-dihydrodiol. J Am Chem Soc. 1986;108:44984504. doi:10.1021/ja00275a040

41. Ellman GL. Tissue sulfhydryl groups. Arch Biochem Biophys. 1959;82:70-77. doi:10.1016/0003-9861(59)90090-6

42. Carmel-Hare O, Storz G. Roles of the glutathione- and thioredoxindependent reduction systems in the Escherichia coli and Saccharomyces cerevisiae responses to oxidative stress. Annu Rev Microbiol. 2000;54:439-461. doi:10.1146/annurev.micro.54.1.439

43. Schniepp HC, Li JL, McAllister MJ, et al. Functionalized single graphene sheets derived from splitting graphite oxide. J Phys Chem B. 2006;110:8535-8539. doi:10.1021/jp060936f

44. Feng X, Li X, Li Z, Liu Y. Size-dependent two-photon absorption in circular graphene quantum dots. Opt Express. 2016;24:2877-2884. doi:10.1364/OE.24.002877

45. Jablonski A. Efficiency of anti-Stokes fluorescence in dyes. Nature 1933;131:839-840. doi:10.1038/131839b0

46. Xu C, Webb WW. Measurement of two-photon excitation cross sections of molecular fluorophores with data from 690 to $1050 \mathrm{~nm}$. J Opt Soc Am B. 1996;13:481-491. doi:10.1364/JOSAB.13.000481

47. Jeon S, Haley J, Flikkema JJ, et al. Linear and nonlinear optical properties of photoresponsive [60]fullerene hybrid triads and tetrads with dual NIR two-photon absorption characteristics. J Phys Chem C. 2013;117:17186-17195. doi:10.1021/jp405424q

48. Kuo WS, Chen HH, Chen SY, et al. Graphene quantum dots with nitrogen-doped content dependence for highly efficient dual-modality photodynamic antimicrobial therapy and bioimaging. Biomaterials. 2017;120:185-194. doi:10.1016/j.biomaterials.2016.12.022

49. Wu PC, Chen HH, Chen SY, et al. Graphene oxide conjugated with polymers: a study of culture condition to determine whether a bacterial growth stimulant or an antimicrobial agent? J Nanobiotechnol. 2018;16:1-20. doi:10.1186/s12951-017-0328-8
International Journal of Nanomedicine

\section{Publish your work in this journal}

The International Journal of Nanomedicine is an international, peerreviewed journal focusing on the application of nanotechnology in diagnostics, therapeutics, and drug delivery systems throughout the biomedical field. This journal is indexed on PubMed Central, MedLine, CAS, SciSearch ${ }^{\circledR}$, Current Contents ${ }^{\circledR} /$ Clinical Medicine, $^{-}$
Journal Citation Reports/Science Edition, EMBase, Scopus and the Elsevier Bibliographic databases. The manuscript management system is completely online and includes a very quick and fair peer-review system, which is all easy to use. Visit http://www.dovepress.com/ testimonials.php to read real quotes from published authors. 